\title{
Screening for gastric carcinoma in coal miners
}

\author{
J D Harrison, D L Morris, J D Hardcastle
}

\begin{abstract}
This study aimed to determine the prevalence of dyspeptic symptoms and premalignant gastric lesions in coal miners and sex matched population control subjects. Retired coal miners and men from the general population in north Nottinghamshire were sent a dyspepsia questionnaire to fill in, and those with upper gastrointestinal symptoms were invited for gastroscopy and biopsy. A total of 1272 men from the general population and 2099 retired coal miners aged 50-75 years took part in the study. Some 977 of $1272(76.8 \%)$ control subjects and 1715 of $2099(81 \cdot 7 \%)$ miners replied to the questionnaire. A total of 308 of $977(31.5 \%)$ controls and 620 of $1715(36 \cdot 2 \%)$ miners were positive for at least one symptom. There was a highly significant difference between the numbers of surface mine and underground workers who reported dyspeptic symptoms (66 of 300 $(22 \%) v 425$ of $1083(32 \cdot 2 \%)$ of $\mathrm{p}<0.0001)$. Histology showed that significantly more miners than controls had acute on chronic gastritis $(22 v 11 \% ; \mathrm{p}=0.01)$ and intestinal metaplasia (23 $v$ 8\%; $\mathrm{p}=<0.0001)$. Coal miners may be a suitable group for gastric premalignancy screening using an upper gastrointestinal symptom questionnaire and upper gastrointestinal endoscopy.

(Gut 1993; 34: 494-498)
\end{abstract}

It has been suggested that gastric cancer which occurs in some manual workers is occupation related. Evidence for such an association has been published in the Registrar General's Decennial Supplements on Occupational Mortality since 1937, but these data have not been highlighted.

The occupational mortality data pertaining to the 1949-53 quinquennium were analysed by Stocks, who showed that there were six conditions which caused a $15 \%$ or greater excess mortality among coal miners (Table I). ${ }^{1}$ The average excess mortality for gastric cancer among coal miners was 126 per million, with a range of 65-226 per million. This excess was greatest in South Wales, intermediate in the north of England, and least in the south of England. Stocks' hypothesised that these find-

TABLE I Excess mortality in coal miners

Department of Surgery, Queen's Medical Centre, Nottingham

J D Harrison

D L Morris,

J D Hardcastle

Correspondence to:

Mr J D Harrison, 5 Longwood Court, Tingley, W Yorkshire WF3 IUW

Accepted for publication

1 September 1992

\begin{tabular}{lc}
\hline & $\begin{array}{c}\text { Standardised } \\
\text { mortality ratio }\end{array}$ \\
\hline Pneumoconiosis & 1277 \\
Gastric carcinoma & 149 \\
Endocarditis & 146 \\
Bronchitis & 135 \\
Myocardial degeneration & 127 \\
Respiratory tuberculosis & 119 \\
\hline Standard mortality ratio=(observed deaths/expected deaths) \\
$\times 100$. \\
Data from Registrar General's Decennial Supplements on \\
Occupational Mortality from 1937.
\end{tabular}

ings could be related to the nature of the coal mined in these different areas. The excess mortality is not limited to underground workers, since workers above ground have a raised standardised mortality ratio (SMR) for gastric cancer (143), which is similar to that for underground workers other than those at the coal face (SMR 144).

It is of note that workers at the coal face (cutters, hewers, and getters) have only a slightly raised SMR for gastric cancer (113) which is not as great as that for the remainder of the mineworkers. ${ }^{2}$ This is probably because the youngest and fittest miners are involved in the more strenuous tasks at the coal face, while the older and less fit do other underground work or gain surface employment. It is likely, however, that the surface workers with the higher SMR for gastric cancer worked underground when they were younger and graduated to a less strenuous and dangerous job with age.

Screening for gastric cancer in Japan has increased the proportion of early gastric cancers diagnosed to approximately $45 \%$ in the screened population. Many studies have shown that these tumours are surgically curable. Mortality from gastric cancer has fallen in areas of Japan where screening has been most widely accepted. ${ }^{3-5}$ In the United Kingdom, however, only $10 \%$ of tumours are early gastric cancers, ${ }^{6}$ so potential exists for changing the natural history of the disease if populations suitable for screening can be identified.

If dyspepsia is to be used to identify a particularly high risk group (such as coal miners), then we must know the rate of dyspepsia in the group we are studying and the extent to which it differs from that in the general population. We have therefore compared a group of coal miners and an age and sex matched group of subjects selected from the members of a general population screening study. Groups received questionnaire screening to see if there are any differences in the rates of dyspepsia between the two with a view to screening the high risk group of miners for gastric cancer. In addition, the dyspeptic members of both groups underwent gastroscopy to determine if there was any evidence of an increased incidence of benign, premalignant, and malignant gastric lesions.

\section{Patients and methods}

A group of 2037 retired coal miners aged $50-75$ years was identified from the records of the North Nottinghamshire Miners' Pension Fund (with the cooperation of the Pension Fund Board and the Union of Democratic Mineworkers). A group of 1199 men who were not coal miners was identified from general practitioner records in three Nottinghamshire general practices. Included in the questionnaire were inquiries 
about tobacco using habits (including tobacco chewing in the questionnaire to miners). When the completed questionnaire had been received, the general practitioner was written to before any further contact with the patient took place.

The questionnaire was sent to the subjects in each of the groups with a reply paid envelope. A reminder letter and questionnaire were sent 6 weeks later to subjects who had not replied by this time.

The signatory of the letter in the case of the miners was Mr Roy Lynk, President of the Union of Democratic Mineworkers but in the case of the general population this was the patient's general practitioner. The letter and questionnaire were as simple as possible to maximise the response.

Subjects with one or more positive replies on the questionnaire, or those who used $\mathrm{H}_{2}$ antagonists or antacids, were invited to attend a dyspepsia clinic where it was decided whether endoscopy was appropriate and the procedure was explained. Those in whom gastroscopy was appropriate were invited to attend the endoscopy unit at a later date (within 1 month). Also included in the questionnaire was a brief occupation history (underground or surface work), and the data were analysed to take account of previous occupation.

The clinic and endoscopy were initially held in Nottingham, but because of relatively poor attendance at the clinic and since a large proportion of the retired miners in the North Nottinghamshire Pension Scheme live in and around Mansfield, a session was held in the endoscopy unit at King's Mill Hospital, Mansfield.

A small number of patients were not contacted further on the advice of their general practitioner, usually because of concurrent malignant disease. Patients were excluded from further examination after their dyspepsia clinic visit if they had severe concurrent cardiovascular or respiratory disease. Patients with other malignant disorders were also excluded from further study, since the early diagnosis of a second malignancy might not be expected to improve their prognosis.

Patients who denied any symptoms, or who gave a history of a single episode of self-limiting dyspeptic symptoms, were also excluded from gastroscopic examination, but all other patients were offered gastroscopy as outpatients.

STATISTICS

The relative proportions of each of the parameters in the miners' and the general population groups were compared for statistical signficance using the $\chi^{2}$ test.

\section{Results}

COMPLIANCE

A total of 977 of $1272(76.8 \%)$ men in the general population and 1715 of $2099(81 \cdot 7 \%)$ miners replied to the questionnaire $\left(\chi^{2}=1 \cdot 33\right.$, NS). Of those who replied, 620 of $1715(36 \cdot 2 \%)$ miners were positive for at least one symptom as were 308 of $977(31 \cdot 5 \%)$ men in the general population group $\left(\chi^{2}=2 \cdot 90, N S\right)$. The attendance of the coal miners at the Nottingham dyspepsia clinic was poor compared with that of the general population: 338 of $620(54 \%)$ compared with 254 of 308 $(82.5 \%)$ respectively $\left(\chi^{2}=14.6, \quad p<0.0001\right)$. There was a significant improvement in the attendance of miners at the Mansfield clinic, however, since this was much closer to their homes. The attendance of miners at Mansfield was 73 of $95(76.8 \%)$ compared with $54.5 \%$ at Nottingham $\left(\chi^{2}=4 \cdot 1, p<0 \cdot 05\right)$.

Once they had attended the clinic and been invited for gastroscopy, a similar proportion of miners and general population attended for gastroscopy (229 of $338(67 \cdot 8 \%)$ and 192 of 254 $(77 \cdot 6 \%)$ respectively $\left.\left(\chi^{2}=0 \cdot 7, \mathrm{NS}\right)\right)$. The reasons for not endoscoping some subjects are given in Table II.

\section{SYMPTOMS}

Comparing each of the symptoms (see Table III), significantly more miners than control subjects complained of anorexia, weight loss, dysphagia, epigastric pain, and vomiting, while similar numbers from both groups complained of heartburn. Significantly more miners had had previous gastric surgery for benign disease, and significantly more miners smoked than did men from the general population. In addition, chewing tobacco is a common habit among coal miners. Altogether $643(30.5 \%)$ of the miners took tobacco in this form either solely or in conjunction with smoking (see Table IV).

\section{Surface $\mathrm{v}$ underground workers}

There was a highly significant difference between the number of mine surface workers who reported dyspeptic symptoms (66 of 300, $22 \%$ ) on the questionnaire and underground workers $(425$ of $1083,39.2 \%), \chi^{2}=30.5$, $\mathrm{p}<0 \cdot 0001$. There were no significant differences

TABLE II Reasons for not performing endoscopy in the two study groups

\begin{tabular}{lll}
\hline & Population & Miners \\
\hline Patient refused & 18 & 36 \\
Inappropriate & 30 & 42 \\
No symptoms & 8 & 21 \\
\hline
\end{tabular}

TABLE III Comparison of symptoms in miners and men from the general population

\begin{tabular}{|c|c|c|c|c|}
\hline Symptom & $\begin{array}{l}\text { Population } \\
(n=1265) \\
n o(\%)\end{array}$ & $\begin{array}{l}\text { Miners } \\
(n=2102) \\
n o(\%)\end{array}$ & $\chi^{2}$ & $p$ \\
\hline Anorexia & $33(2 \cdot 6)$ & $171(8 \cdot 1)$ & $38 \cdot 0$ & $<0.0001$ \\
\hline Weight loss & $19(1 \cdot 5)$ & $148(7 \cdot 0)$ & $47 \cdot 2$ & $<0.0001$ \\
\hline Dysphagia & $35(2 \cdot 8)$ & $93(4 \cdot 4)$ & $5 \cdot 5$ & 0.05 \\
\hline Epigastric pain & $150(11 \cdot 9)$ & $314(14.9)$ & $4 \cdot 8$ & 0.05 \\
\hline Heartburn & $235(18 \cdot 8)$ & $454(21 \cdot 6)$ & $2 \cdot 9$ & NS \\
\hline Vomiting & $48(3 \cdot 8)$ & $133(6 \cdot 3)$ & $8 \cdot 9$ & 0.01 \\
\hline Previous gastric surgery & $40(3 \cdot 2)$ & $137(6 \cdot 5)$ & $16 \cdot 2$ & $<0.001$ \\
\hline
\end{tabular}

TABLE IV Smoking status in miners and men from the general population

\begin{tabular}{|c|c|c|c|c|}
\hline Smoking status & $\begin{array}{l}\text { Population } \\
(n=1253) \\
\text { no }(\%)\end{array}$ & $\begin{array}{l}\text { Miners } \\
(n=2102) \\
\text { no }(\%)\end{array}$ & $\chi^{2}$ & $p$ \\
\hline $\begin{array}{l}\text { Current smoking } \\
\text { Tobacco chewing }\end{array}$ & $\begin{array}{c}169(13 \cdot 5) \\
-\end{array}$ & $\begin{array}{l}620(29 \cdot 5) \\
643(30 \cdot 6)\end{array}$ & $\begin{array}{l}71 \cdot 9 \\
-\end{array}$ & $\begin{array}{l}<0.0001 \\
-\end{array}$ \\
\hline
\end{tabular}


between the surface and underground workers for attendance at the dyspepsia clinic or the endoscopy unit.

\section{Age}

There were no statistically signficant differences between the age groups analysed for the number of questionnaires returned or the dyspepsia rate (which was highest in the 61-65 year age group, although the numbers in this group were small). There was a trend towards a decline in attendance at both the dyspepsia clinic and the endoscopy unit with increasing age, but this was not statistically significant. The age composition of the mining group was significantly older than that of the general population group, since the source of the coal miners was a group of retired men.

\section{Medical treatment}

Compared with the general population, significantly more miners had visited their general practitioner because of dyspepsia either recently or at some time in the past $(80 \% v 55 \cdot 1 \%$, $\mathrm{p}<0.001)$. There was no significant differences between the groups for consumption of nonsteroidal anti-inflammatory drugs (miners $12.9 \%$, population $16.6 \%), \mathrm{H}_{2}$ antagonists (miners $6.7 \%$, population $11.4 \%$ ), or simple antacids (miners $42 \cdot 1 \%$ population $54 \cdot 2 \%$ ).

\section{Endoscopy}

The endoscopic findings in each group are summarised by site in Tables V and VI. It is notable that oesophageal and gastric inflammatory pathology was common in these symptomatic patients. There was a slight preponderance of hiatus hernia in the control group and of Barrett's oesophagus in the miners' group, but these were not statistically significant.

TABLE V Oesophageal, endoscopic, and histological results

\begin{tabular}{lcl}
\hline & Population no $(\%)$ & Miners no $(\%)$ \\
\hline Endoscopy-oesophagus & & \\
Mild oesophagitis & $87(45)$ & $95(47)$ \\
Moderate oesophagitis & $29(15)$ & $17(8)$ \\
Severe oesophagitis & $5(3)$ & $14(7)$ \\
Hiatus hernia & $51(26)$ & $37(18)$ \\
Barrett's & $11(6)$ & $18(9)$ \\
Peptic stricture & $2(1)$ & $1(0 \cdot 5)$ \\
Histology-oesophagus & & \\
Mild oesophagitis & $73(60)$ & $54(45)$ \\
Moderate oesophagitis & $14(11)$ & $10(8)$ \\
Severe oesophagitis & $7(6)$ & $9(8)$ \\
Barrett's & $7(6)$ & $9(8)$ \\
Intestinal metaplasia & $5(4)$ & $9(8)$ \\
\hline
\end{tabular}

TABLE VI Gastric, endoscopic, and histological results

\begin{tabular}{lcc}
\hline & Population no $(\%)$ & Miners no $(\%)$ \\
\hline Endoscopy-stomach & $143(74)$ & $203(89)$ \\
Gastritis & $15(8)$ & $12(5)$ \\
Erosions & $6(3)$ & $7(3)$ \\
Polyps & $1(0 \cdot 6)$ & - \\
Carcinoma & $64(37)$ & $86(42)$ \\
Histology-stomach & $20(12)$ & $21(10)$ \\
Chronic gastritis & $19(11)$ & $44(22)^{\star}$ \\
Acute gastritis & $6(3)$ & $7(3)$ \\
Acute on chronic gastritis & $1(0 \cdot 9)$ & - \\
Hyperplastic polyps & $7(3)$ & $6(3)$ \\
Adenocarcinoma & $14(8)$ & $46(23)^{\star \star}$ \\
Dysplasia &
\end{tabular}

${ }^{\star} \chi^{2}=5 \cdot 35, \mathrm{p}=0.01 ;{ }^{\star} \chi^{2}=10 \cdot 65, \mathrm{p}=<0 \cdot 0001$.

\section{Histology}

Gastritis was also common. There was a significant excess of subjects with acute on chronic gastritis in the miners' group, and in addition, nearly three times as many miners had intestinal metaplasia in their gastric biopsy specimens. We were unable to subclassify the type of intestinal metaplasia in this study.

\section{Discussion}

Most of the data in the published reports to date (including those of the Registrar General for England and Wales) support the conclusion that coal miners have an average excess mortality for gastric cancer of approximately $30-50 \%$, rising to five fold in some regions, although some studies have failed to show this excess. ${ }^{78}$

A number of hypotheses to account for an excess mortality have been proposed, including an effect of socioeconomic status. ${ }^{19}$ Socioeconomic status has been considered important because miners were of social class $\mathrm{V}$ earlier this century and this class has a $50 \%$ excess for gastric cancer compared with the higher social classes.

In two Utah mining counties (Carbon and Emery), the age and sex adjusted death rate for gastric cancer was 3.4 times higher than that for the rest of the state overall, and eight times higher in miners than in non-mining Utah men. ${ }^{10}$ The excess mortality was attributed to coal mining and the extensive use of soft coal in the mining areas.

A larger study of 23 mining counties in the USA showed an excess mortality of approximately $30 \%$. Excesses were also seen for the tumours associated with low socioeconomic class (lung and cervical cancer), while deficiencies were noted for breast and colon cancer that are usually associated with higher socioeconomic class. The authors thus concluded that the excess mortality noted for gastric cancer was probably related to socioeconomic class rather than coal mining. ${ }^{9}$

In a study of 23232 miners, excess mortality was noted for benign respiratory conditions, accidents, and gastric cancer. The excess for gastric cancer was noted only for men over 70 years of age."

Coal dust exposure is an occupational hazard for coal miners. The dust contains a variety of minerals such as quartz, pyrite, dolomite, siderite, magnetite, and a variety of silicates. There are also metals including aluminium, iron, magnesium, potassium, and sodium. Organic compounds including a number of carcinogenic polycyclic aromatic hydrocarbons are also present in coal dust. When coal dust is inhaled, particles are cleared by the cilia of the respiratory mucosa into the pharynx, where they are swallowed thereby exposing the upper gastrointestinal mucosa to these compounds contained in the dust. ${ }^{12}$

Mutagenesis experiments with coal dust using the Ames salmonella assay ${ }^{13}$ have found extracts of American coal dust to be mutagenic (and mutagenicity has a broad correlation with carcinogencity). This mutagenicity is enhanced by nitrosation in acid conditions. This is one hypothesis by which coal miners may have an 
increased risk of developing gastric cancer, ${ }^{1+}$ although it has been noted recently that not all carcinogens are mutagens. ${ }^{15}$

The quantification of dust exposure is often difficult but there is some evidence that there is a relationship between exposure to dust and the degree of increased risk of developing gastric cancer. ${ }^{16}$ Ames $^{17}$ showed in a case-control study that prolonged dust exposure was not an independent risk factor, but an increased risk was seen in association with dust exposure and cigarette smoking.

Other hypotheses relate to the potentially carcinogenic effects of coal dust alone, ${ }^{17}$ or after conversion of aromatic coal derivatives to mutagenic nitroso-compounds in the stomach. ${ }^{18}$ Another study has shown a positive association between gastric cancer and exposure to coal dust in those miners who smoked. ${ }^{19}$ Polynuclear aromatic compounds have been shown to be effective as carcinogens, especially when in particulate form, ${ }^{20}$ while statistical associations have been noted in men between atmospheric pollution and coal mining. ${ }^{21}$

Another possible factor resulting in an increased gastric cancer risk is the more common use of tobacco by coal miners. The carcinogenic effects of smoking on the respiratory tract are well known, but the effect of smoking on the stomach is less well known, although there is much circumstantial evidence that smokers are at a higher risk of developing gastric carcinoma. ${ }^{22} 23$ There have also been studies to suggest that unburned tobacco in the form of snuff or chewing tobacco has a carcinogenic effect on gastric mucosa. ${ }^{182425}$ It is thus of note that $27 \%$ of coal miners in our survey have a history of chewing tobacco. Other studies have shown that smoking is an aetiological factor for gastric cancer either by itself, or more potently when in combination with another factor such as coal dust exposure ${ }^{17}$ or the consumption of alcohol. ${ }^{26}$

In our study, significantly more miners complained of anorexia and weight loss than the general population, as shown in an earlier published report. ${ }^{27}$ This may be related to the destabilisation of the gastric mucosa engendered by a lifetime of exposure to the environmental conditions in coal mines, although clearly these symptoms could also be related to the asthenia of chronic respiratory disease which is so common in coal miners. We did not quantitate respiratory disease or dust exposure in our study, and hence we are unable to assess the effect of this variable.

Also relevant in the context of increased risk of gastric cancer is the finding that significantly more miners have had surgery for benign peptic ulcer disease $(7 \cdot 7 \% v 4 \%, \mathrm{p}=<0 \cdot 001)$. A recent review confirmed the increase in risk of developing a gastric carcinoma after gastric resection..$^{28}$

The miners had significantly more acute-onchronic gastritis in their endoscopic biopsy speci mens. The cause for this is not clear but one factor could be the higher proportion of miners who had had gastric surgery. Another possibility is that there could be a relationship between this inflammation and infection with Helicobacter pylori, although we are unable to confirm this from our study, since the organism was not specifically looked for in every case. There are no studies in the literature to date linking miners with an increased risk of developing gastric $H$ pylori infection.

It is also of note that there was a higher proportion of gastric and duodenal ulcers in the group of miners, and there was a significantly higher number of miners with the premalignant histological lesions of dysplasia and intestinal metaplasia compared with the general population.

Miners are thus a high risk group for the development of gastric cancer and gastroscopic screening could give a significant yield of early gastric cancers.

It is evident that there is a variety of occupations in which an excess mortality has been described for gastric cancer. ${ }^{29-36}$ but the largest occupational group with such an excess in the United Kingdom is the coal miners. In south Wales the gastric cancer registration rates in miners are higher than in England, and it has been suggested that coal miners in urban areas should be considered as a high risk group suitable to be screened for the disease by the instigation of dyspepsia clinics. ${ }^{37}$

The group of coal miners in this study complained more frequently of anorexia and weight loss, had a higher prevalence of previous gastric surgery, and included a higher proportion of smokers than an age and sex matched group of men from the general population. Endoscopy showed that the miners had a higher incidence of gastritis than the men from the general population. Histology showed that there were more premalignant lesions (intestinal metaplasia and dysplasia) in the miners than in the control group. These findings could help to explain the higher incidence of gastric cancer among coal miners and we suggest that this would be a suitable group to screen for premalignant gastric pathology using an upper gastrointestinal symptom questionnaire.

1 Stocks P. On the death rates from cancer of the stomach and respiratory diseases in 1949-53 among coal miners and othe male residents in counties of England and Wales. $\mathrm{Br} \mathscr{f}$ Cancer 1961; 16: 592 .

2 Registrar General. Statistical Review for England and Wales 1937-1973. London: HMSO, 1937

3 Kaneko E, Nakamura T, Umeda N, Fujino $M$, Niwa $H$. Outcome of gastric carcinoma detected by gastric mass survey in Japan. Gut 1977; 18: 226.

4 Okui K, Tejima H. Evaluation of gastric mass survey. Acto Chir Scand 1980; 146: 185.

5 Kohrogi N. A study on the efficiency of gastric cancer screening with special reference to the appropriate frequency of screening. Fukuoka Igaku Zasshi 1987; 78: 67.

6 Ballantyne K, DL DM, Jones J, RH RG, Hardcastle J Accuracy of identification of early gastric cancer. $\operatorname{Br} \mathcal{F}$ Surg 1987; 74: 618

7 Davies J. Stomach cancer mortality in Worksop and other Nottinghamshire mining towns. Br f Cancer $1980 ; 41$ (3): 438.

8 Swaen G Aerdts CW, Slangen JJ. Gastric cancer in coal miners: final report. $B r \mathcal{F}$ Ind Med 1987; 44: 777 .

9 Creagan E, Hoover R, Fraumeni J. Mortality from stomach cancer in coal mining regions. Arch Environ Health 1974;28: 28.

10 Matolo N, Klauber M, WM WG, Dixon J. High incidence of gastric carcinoma in a coal mining region. Cancer 1972; 29 . gastric

11 Rockette $\mathrm{H}$. Cause specific mortality of coal miners. $\mathcal{F}$ ()ccup Med 1977; 19 (12): 795

12 Lippmann M, Yeates D, Albert R. Deposition, retention, and clearance of inhaled particles. Br F Ind Med 1980;37:337.

13 Ames B, McCann J, Yamasaki E. Methods for detecting carcinogens and mutagens with the salmonella/mammalian microsome mutagenicity test. Mutat Res 1975; 31:347.

14 Ames R. Gastric cancer in coal miners: some hypotheses for investigation. F Soc Occup Med 1982; 32: 73 .

15 Ames B, Gold L. Too many rodent carcinogens: mitogenesis increases mutagenesis. Science 1990; 249: 970. 
16 Wright W, Bernstein L, Peters J, Garabrant D, Mack T Adenocarcinoma of the stomach and exposure to occupational dust. Am 7 Epidemiol 1988; 128: 64 .

17 Ames R. Gastric cancer and coal mine dust exposure. A case control study. Cancer 1983; 52: 1346.

18 Ong T, Whong W, Ames R. Gastric cancer in coal miners: an hypothesis of coal mine dust causation. Med Hypotheses 1983; 12: 159 .

19 Ames R, Gamble J. Lung cancer, stomach cancer, and smoking status among coal miners. A preliminary test of a

20 Falk H, Jurgelski W. Health effects of coal mining and combustion: carcinogens and cofactors. Environ Health Perspect 1979; 33: 203

21 Ashley D. Environmental factors in the aetiology of gastric cancer. Brf Prev Soc Med 1969; 23: 187

22 Zacho A, Nielsen J, Larsen V. On the consumption of unburned tobacco in patients with carcinoma of the stomach. Acta Chir Scand 1968; 134: 272 .

23 Wang $\mathrm{H}$, Antonioli $\mathrm{D}$, Goldman $\mathrm{H}$. Comparative features of esophageal and gastric adenocarcinomas: recent changes in type and frequency. F Hum Pathol 1986; 17 (5): 482.

24 Desai $H$, Venugopalan $K$, Antia $F$. Effect of intragastric infusion of tobacco powder on DNA content of gastric infusion of tobacco powder on
aspirate. Dig Dis $1975 ; 20(5): 450$.

25 Taylor R, Piper D. The carcinogenic effect of cigarette smoke. The effect of cigarette smoke on human gastric mucosal cells in organ culture. Cancer 1977; $39(6): 2520$.

26 Hoey J, Montvernay C, Lambert R. Wine and tobacco: risk factors for gastric cancer in France. Am $\mathcal{F}$ Epidemiol 1981; $113(6)$ : 668.
27 Harrison J, Morris D. A comparative study of dyspepsia in coal miners and the general population. Br F Ind Med 1989 46: 428

28 Elder J, Knight T. Surgical Suppression of Gastric Acid Secretion: lessons from long-term follow-up studies. Scand $\mathcal{F}$ Gastroenterol 1991; 26 (suppl 188): 26.

29 McDonald J, Becklake M, Gibbs G, McDonald A, Rossiter C. The health of chrysotile asbestos mine and mill workers of Quebec. Arch Environ Health 1977; 28: 61 .

30 Enterline P, DeCoufle P, Henderson V. Mortality in relation to occupational exposure in the asbestos industry. $\mathcal{F}$ Occup Med 1972; 14: 897.

31 Botha J, Irwig L, Strebel P. Excess mortality from stomach cancer, lung cancer and asbestosis and/or mesothelioma in crocidolite mining districts in South Africa. Am $\mathcal{F}$ Epidemiol 1986; 123: 30

32 Parkes H, Veys C, Waterhouse J, Peters A. Cancer mortality in the British rubber industry. Br f Ind Med 1982; 39: 209.

33 Sorahan T, Parkes H, Veys C, Waterhouse J. Cancer mortality in the British rubber industry: 1946-1980. Br f Ind Med 1986; 43: 363 .

34 Rushton L, Alderson M. An epidemiological survey of eight oil refineries in Britain. BrF Ind Med 1981; 38: 225.

35 Jarvholm B, Lillienberg L, Sallsten G, Thiringer G, Axelson $\mathrm{O}$. Cancer morbidity among men exposed to oil mist in the O. Cancer morbidity among men exposed
metal industry. F Occup Med 1981; 23: 333.

36 Dubrow R, Gute D. Cause-specific mortality among Rhode Island jewelry workers. Am F Ind Med 1987; 12: 579

37 Craven J, Baum M, West R. Variations in gastric cancer mortality in South Wales. Clin Oncol 1979; 5 (4): 341. 